\title{
CRESCIMENTO E RENDIMENTO PRODUTIVO DO FEIJOEIRO SUBMETIDO À RESTRIÇÃO HÍDRICA
}

Sandro Dan Tatagiba ${ }^{1}$, Kelly Juliane Telles Nascimento ${ }^{2}$, Gustavo Adolfo Bevitori Kling Moraes ${ }^{3}$, Anelisa de Figueiredo Peloso ${ }^{4}$

\section{RESUMO}

A cultura do feijoeiro é afetada pelas condições climáticas, sendo o desenvolvimento das plantas influenciado pelo estresse hídrico. Um dos modos de se suprir as necessidades das plantas é por meio da irrigação. Dessa forma, buscouse investigar neste trabalho o crescimento vegetativo e o rendimento produtivo do feijoeiro submetido à restrição hídrica durante o seu ciclo. Para esta finalidade, plantas de feijoeiro cultivar Manteiga foram cultivadas em vasos de $5 \mathrm{dm}^{3}$ e submetidas aos tratamentos de 50 e 100\% da capacidade de campo. Os parâmetros analisados foram: altura da planta, área foliar, número de nódulos do sistema radicular, matéria seca da parte aérea, da raiz e total, massa seca de grãos e número de grãos e de vagens. De acordo com os dados obtidos, foram determinados os seguintes índices de crescimento: incremento de matéria seca total, do caule, da folha, e da raiz. O experimento foi realizado em casa de vegetação, no Campus da Universidade Federal de Viçosa, disposto num delineamento experimental de blocos casualizados, em esquema de parcelas subdivididas no tempo, com quatro repetições. Os resultados obtidos mostraram que houve um menor crescimento vegetativo e menor rendimento produtivo nas plantas submetidas à restrição hídrica, imposta pelo tratamento de 50\% da capacidade de campo, evidenciando a necessidade do controle adequado de água no solo como estratégia de manejo adequado para a produção.

Palavras-chave: Phaseolus vulgaris, déficit hídrico, análises de crescimento, produção

\section{ABSTRACT \\ GROWTH AND PRODUCTION EFFICIENCY OF THE COMMOM BEAN SUBMITTED TO WATER RESTRICTION}

The bean crop is affected by climate conditions, where plant development is influenced by water stress. One of the ways to meet the needs of the plant is through irrigation. Thus, in this work we sought to investigate the vegetative growth and production yield of the bean subjected to water stress during its cycle. For this purpose, beans of the cultivar Manteiga were cultivated in $5 \mathrm{dm}^{3}$ pots and subjected to treatments of 50 and $100 \%$ field capacity. The parameters analyzed were: plant height, leaf area, number of root nodules, dry weight of the shoots, roots and total, dry mass of the grains and grain number and grain yield. According to the data obtained the following growth indexes were determined: increase of total dry matter and that of the stem, leaf and root. The experiment was conducted in a greenhouse at the Federal University of Viçosa, arranged in a randomized complete block design in a split-plot in time, with four replications. The results showed that there was lower vegetative growth and lower production yield in plants subjected to water restriction, imposed by the treatment of 50\% field capacity, indicating the need for adequate control of soil water management as a suitable strategy for production.

Keywords: Phaseolus vulgaris, water deficit, growth analysis, production

Recebido para publicação em 22/02/2013. Aprovado em 22/07/2013.

1 - Engenheiro Agrônomo, Doutor em Fisiologia Vegetal, UFV/Viçosa-MG, E-mail: sandrodantatagiba@yahoo.com.br

2 - Engenheira Agrônoma, Doutora em Fisiologia Vegetal, UFV/Viçosa-MG, E-mail: kellytelles@gmail.com

3 - Engenheiro Agrônomo, Doutorando em Fisiologia Vegetal, UFV/Viçosa-MG, E-mail: gustavo.kling@gmail.com

4 - Engenheira Agrônoma, UFV/Boa Esperança-MG, E-mail: anelisapeloso@yahoo.com.br 


\section{INTRODUÇÃO}

A produção de legumes é de suma importância nos sistemas agrícolas em todo o mundo. Em regiões tropicais e subtropicais, o feijoeiro (Phaseolus vulgaris L.) destaca-se como importante fonte de proteína para mais de 500 milhões de pessoas na América Latina e África (NIELSEN et al., 1999). Considerando todos os gêneros e espécies de feijoeiro, a produção anual de feijão gira em torno de 25,0 milhões de tonelada, ocupando uma área de 23,2 milhões de hectares divididos em 117 países em todo o mundo (FAO, 2009). A necessidade hídrica do feijoeiro é variável, sendo influenciada por fatores tais como época de semeadura, variedade, condições edafoclimáticas e estádio de desenvolvimento (MOREIRA et al., 1996). O feijoeiro é considerado uma planta sensível ao déficit hídrico devido à baixa capacidade de recuperação após a ocorrência de deficiência hídrica no solo. (GUIMARÃES 1996). Os efeitos da deficiência hídrica sobre o feijoeiro manifestamse ao longo de seu ciclo e nas diferentes partes da planta. Em geral, os efeitos da deficiência hídrica no crescimento e desenvolvimento da cultura limitam a produtividade (MAÑAS \& VALERO 1993).

O crescimento de um vegetal depende, em termos gerais, da divisão, do desenvolvimento e da expansão celular, processos sensíveis ao déficit hídrico, principalmente na fase de alongamento celular. A água, além de ser o principal constituinte do protoplasma, participa diretamente de inúmeras reações químicas, responsáveis pela turgescência celular. A redução da absorção de água e a consequente desidratação das células comprometem os processos fisiológicos afetando, assim, todos os componentes de crescimento (PÁEZ et al., 1995).

As respostas das plantas às variações na disponibilidade hídrica do solo podem ocorrer em curto espaço de tempo, incluindo-se alterações morfológicas, fisiológicas, bioquímicas e moleculares (PASSIOURA, 1997). Essas respostas podem contribuir a fim de diminuir o impacto da deficiência hídrica na produção. Entretanto, as respostas das plantas à deficiência hídrica são dependentes da cultivar, da severidade do estresse hídrico e de sua duração (MÜLLER; WHITSITT, 1996). Em estudo realizado por Carlesso et al. (2007), foi observado que a maior demanda de água pelo feijoeiro ocorreu durante a fase de florescimento até a de enchimento dos grãos, fase correspondente ao maior índice de área foliar e de aumento na atividade fotossintética das plantas. De acordo com Nóbrega et al. (2001), o consumo de água aumenta de um valor mínimo na germinação até um valor máximo na floração e na formação de vagens, decrescendo a partir do início da maturação.

Diante desses aspectos, evidencia-se a necessidade do monitoramento da água no solo a fim de favorecer o estabelecimento de uma estratégia efetiva de manejo, visando à obtenção de rendimentos satisfatórios e lucrativos para o cultivo do feijoeiro. Sendo assim, buscou-se, neste estudo, avaliar o desempenho do crescimento vegetativo e o rendimento produtivo do feijoeiro durante o ciclo cultural, submetido ou não à restrição hídrica.

\section{MATERIAL E MÉTODOS}

$\mathrm{O}$ experimento foi conduzido em casa de vegetação, pertencente à Unidade de Crescimento de Plantas do Departamento de Biologia Vegetal da Universidade Federal de Viçosa, no município de Viçosa-MG, localizado a $20^{\circ} 45^{\prime} \mathrm{S}$ e $42^{\circ} 52^{\prime} \mathrm{W}$ e $648 \mathrm{~m}$ de altitude.

Plantas da cultivar de feijão Manteiga foram crescidas em vasos plásticos contendo $5 \mathrm{dm}^{-3} \mathrm{de}$ substrato, constituído de uma mistura de terra extraída da camada de 0,40 a $0,80 \mathrm{~m}$ de profundidade de um latossolo vermelho amarelo, areia lavada e esterco bovino na proporção $3: 1: 1$, respectivamente. Foi realizada análise granulométrica do substrato, obtendo-se a classificação textural como francoarenoso (Quadro 1).

Amostras do substrato foram analisadas, resultando em boa disponibilidade de bases trocáveis $\left(\mathrm{SB}=5,97 \mathrm{cmol}_{\mathrm{c}} \mathrm{dm}^{-3}\right.$ ) e de saturação de bases $(\mathrm{V}=76 \%)$ e boa disponibilidade de fósforo $\left(\mathrm{P}=222 \mathrm{mg} \mathrm{dm}^{-3}\right)$. No plantio não foi necessário realizar adubação e correção da acidez do solo. A adubação de cobertura foi realizada de acordo com o Arquivo do Agrônomo da Potafos (ROSOLEM; MARUBAYASHI, 1994). Durante o período 
Quadro 1. Análise granulométrica das proporções existentes de cada fração no substrato

\begin{tabular}{|c|c|c|c|c|}
\hline Areia grossa $(0,201 \mathrm{~mm})$ & Areia fina $(0,053 \mathrm{~mm})$ & Areia Total & Argila $(<0,002 \mathrm{~mm})$ & Silte \\
\hline 578,10 & 94,10 & 672,20 & 187,10 & 140,7 \\
\hline
\end{tabular}

Quadro 2. Caracterização do ciclo de crescimento e desenvolvimento da cultivar de feijoeiro Manteiga

\begin{tabular}{cc}
\hline Dias após a Emergência (DAE) & Estádios de crescimento e desenvolvimento \\
\hline $1-22$ & Vegetativo \\
\hline $22-36$ & Floração \\
\hline $36-50$ & Enchimento de grãos \\
\hline $50-64$ & Maturação \\
\hline
\end{tabular}

experimental foram realizadas três adubações de cobertura com o adubo formulado, NPK (30-0630), fornecendo $50 \mathrm{mg}$ durante a terceira, quarta e quinta semanas de cultivo. Em cada um dos vasos foram plantadas quatro sementes de feijão e no oitavo dia, após o plantio, foi realizado o desbaste, deixando apenas duas plântulas em cada vaso. Os dados climáticos de temperatura e umidade relativa do ar foram obtidos utilizando um termohidrógrafo, instalado dentro da casa de vegetação onde foi conduzido o experimento.

O substrato foi previamente peneirado e destorroado (EMBRAPA, 1997). Os valores médios, resultantes de cinco repetições para densidade de partículas, densidade do solo, porosidade total e umidade do solo para o cálculo dos níveis de água, foram $2,39 \mathrm{~kg} \mathrm{dm}^{-3} ; 1,18 \mathrm{~kg}$ $\mathrm{dm}^{-3} ; 53,23 \%$ e $17,31 \%$, respectivamente. Para o estabelecimento do estresse hídrico, foram utilizados dois níveis de água, definidos a partir da porosidade total do solo, com valores de 50 e $100 \%$ do volume total de poros ocupados por água (Capacidade de Campo) e o controle da irrigação foi realizado pelo método gravimétrico (pesagem diárias dos vasos), adicionando-se água até que a massa do vaso atingisse o valor prévio determinado, considerando-se a massa do solo e de água, conforme metodologia descrita por Freire et al (1980).

As coletas das variáveis-resposta foram realizadas semanalmente, por um período consecutivo de oito semanas, iniciadas após o décimo quinto dia da emergência das plantas e sete dias após o início da aplicação dos tratamentos. Em cada coleta, foram analisados os seguintes parâmetros: altura da planta, área foliar, número de nódulos do sistema radicular, matéria seca total (folha, caule e raiz), da parte aérea (folha e caule) e da raiz. A produção foi mensurada através da massa seca de grãos, número de grãos e o número de vagens por planta, realizada aos 64 dias após a emergência (DAE). Com base nos dados obtidos, foram determinados os seguintes índices de crescimento, de acordo com Hunt (1990): incremento de matéria seca total, do caule, da folha, e da raiz. O resumo do ciclo de crescimento e desenvolvimento da cultivar de feijoeiro Manteiga está caracterizado no Quadro 2.

A área foliar foi determinada com o auxílio de um integrador de área foliar (Area Mater MK2). A matéria seca foi obtida com o auxílio de uma estufa com ventilação forçada, a $75{ }^{\circ} \mathrm{C}$, até atingir peso constante.

O delineamento experimental utilizado foi o de blocos casualizados, num esquema de parcelas subdivididas no tempo $(15,23,29,36,43,50,57$ e $64 \mathrm{DAE}$ ), com quatro repetições. Cada unidade experimental foi constituída de um vaso contendo duas plantas. Os dados obtidos foram submetidos à análise de variância e as médias foram comparadas pelo teste $t(P \leq 0.05)$ utilizando-se o software SAS versão 6.12 (SAS Institute, Inc., Cary, NC). 


\section{RESULTADOS E DISCUSSÃO}

As temperaturas máxima ( $\mathrm{T}$ máxima), média (T média) e mínima ( $\mathrm{T}$ mínima) do ar durante o cultivo do feijoeiro estão mostradas na Figura 1a. Durante todo o período de desenvolvimento do feijoeiro, as temperaturas médias mantiveram-se acima de $20{ }^{\circ} \mathrm{C}$, observando alguns valores que ultrapassaram $25{ }^{\circ} \mathrm{C}$. O feijoeiro é uma planta sensível a altas e baixas temperaturas, sendo a temperatura média ótima para o cultivo entre 18 e $24{ }^{\circ} \mathrm{C}$. Temperaturas médias acima de $30{ }^{\circ} \mathrm{C}$ e abaixo de $12{ }^{\circ} \mathrm{C}$ podem ocasionar em certas cultivares, abortamento de flores, vagens e grãos, com consequente queda de rendimento (JUNIOR; VENZON, 2007). A umidade relativa média do ar (UR média) manteve-se acima de $50 \%$, enquanto que os valores da umidade relativa máxima (UR máxima) e mínima (UR mínima) registradas foram de $88 \%$ e $24 \%$, respectivamente (Figura $1 \mathrm{~b}$ ).

A altura apresentou redução significativa de $88,114,54,62,49,36$ e $37 \%$ aos $15,22,29,36$, 43, 50 e 57 DAE, respectivamente, nas plantas submetidas a $50 \%$ da capacidade de campo $(50 \%$ da CC) em relação às plantas submetidas a $100 \%$ da capacidade de campo (100\% da CC), evidenciando que a restrição hídrica diminuiu o crescimento (Figura 2a). Aos $36 \mathrm{DAE}$, as plantas submetidas a $100 \%$ da CC apresentaram máximo valor em altura, após esse período foi observada redução na altura, podendo estar associada com a exportação preferencial de fotoassimilados para o desenvolvimento das flores e posterior emissão das vagens. As plantas submetidas a $50 \%$ da $\mathrm{CC}$ não apresentaram a mesma resposta para a altura, uma vez que a restrição hídrica diminuiu o crescimento das plantas.

A área foliar apresentou redução significativa de $85,142,100,95,46$ e $36 \%$ aos $15,22,29$, 36,43 e 50 DAE, respectivamente, nas plantas submetidas a $50 \%$ da $\mathrm{CC}$ em comparação às plantas submetidas a $100 \%$ da CC (Figura 2b). Os valores de área foliar encontrados no tratamento de $50 \%$ da CC estão de acordo com os resultados obtidos por Moreira (2004) e Pimentel e Perez (2000), onde a taxa de crescimento da área foliar

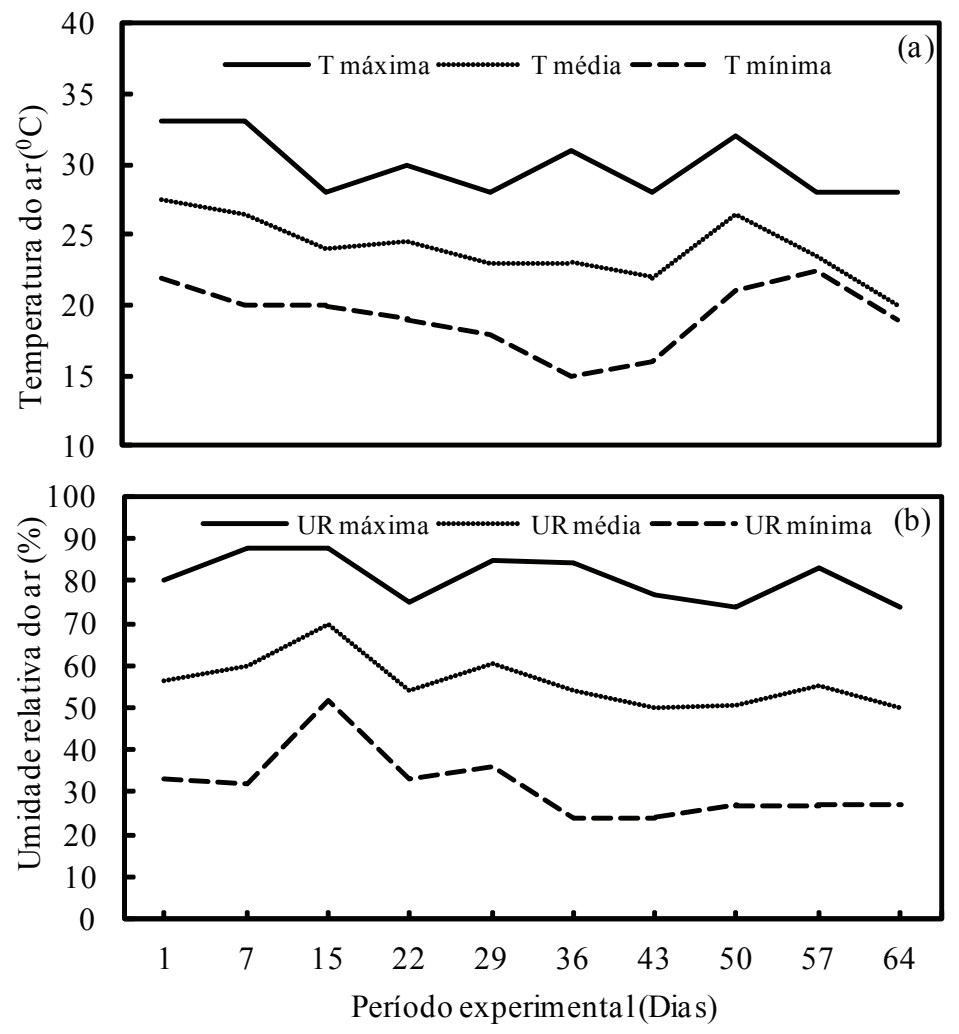

Figura 1. Temperatura (a) e umidade relativa do ar (b) durante o período experimental. 

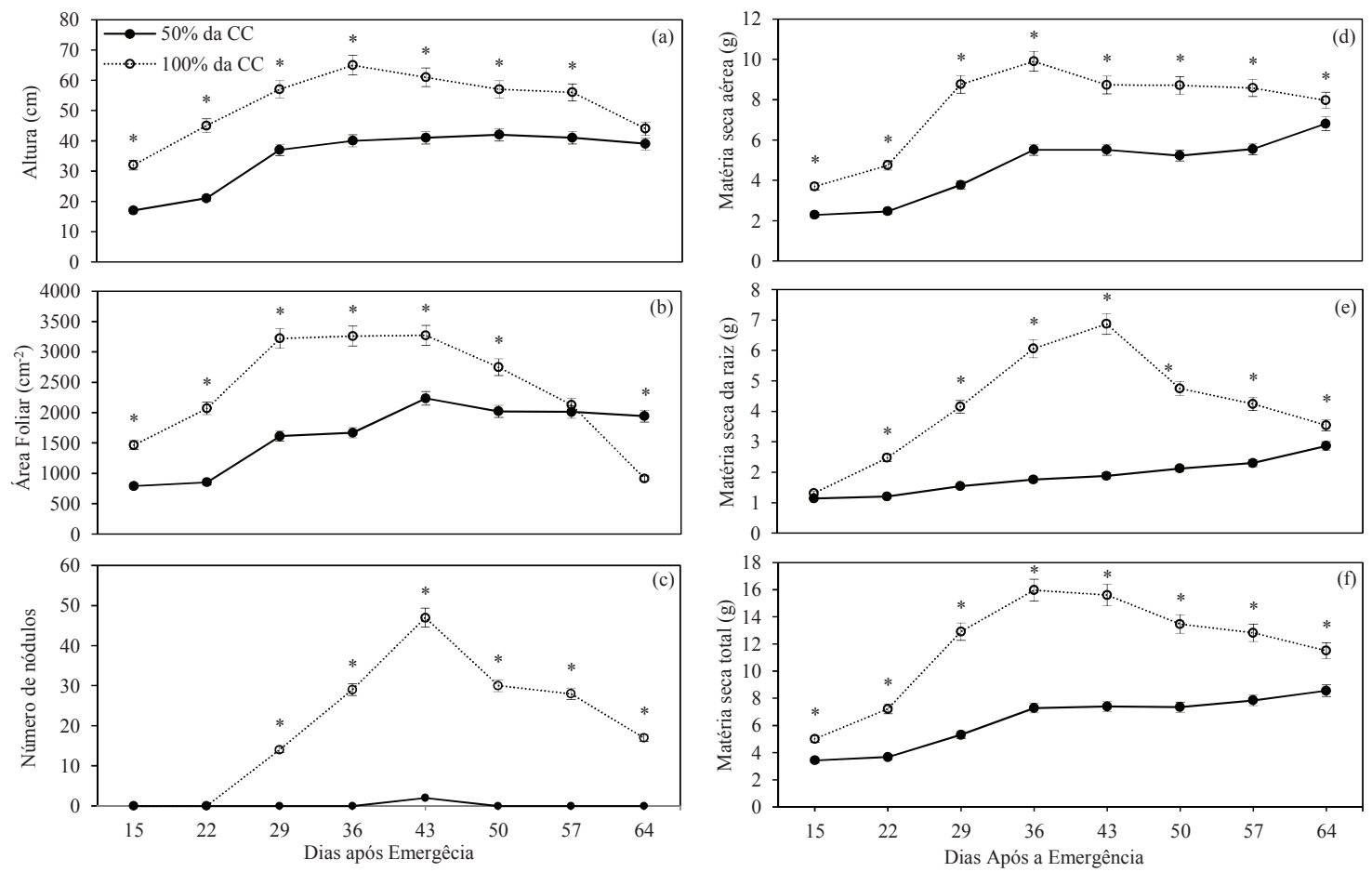

Médias dos tratamentos de 50 e $100 \%$ da capacidade de campo para cada época de avaliação seguidas de asteriscos $(*)$ são significativamente diferentes pelo teste $t$, em nível de $5 \%$ de probabilidade. Barras em cada ponto representam o erro padrão da média.

Figura 2. Altura (a), área foliar (b), número de nódulos (c), matéria seca da parte aérea (d), da raiz (e) e total (f) durante o ciclo cultural do feijoeiro submetido a 50 e $100 \%$ da capacidade de campo.

do feijoeiro decresceu com a deficiência de água. Blum (1997) ressalta que a diminuição da atividade fotossintética e da produtividade de plantas submetidas ao déficit hídrico tem uma grande correlação com a redução da área foliar. De acordo com Taiz e Zeiger (2009), a resposta ao déficit hídrico limita o tamanho e o número de folhas, levando a redução no consumo de carbono e energia por esse órgão da planta. A área foliar tem sua importância por ser um parâmetro indicativo da produtividade, pois o processo fotossintético depende da interceptação da energia luminosa e sua conversão em energia química, sendo este um processo que ocorre diretamente na folha, atuando na formação de carboidratos, que são alocados para os órgãos vegetativos e reprodutivos (BASTOS et al., 2002). Conforme Benincasa (2003), as folhas são os centros de produção de matéria seca (fotossíntese), enquanto o resto da planta depende da exportação de material da folha.

Para a maioria das culturas, a área foliar aumenta rapidamente até atingir o máximo crescimento vegetativo, decrescendo posteriormente com o desenvolvimento da cultura. Esse comportamento indica que, inicialmente, a maior parte do material fotossintetizado é convertida em folhas, visando à maior captação de radiação solar disponível (PEREIRA; MACHADO 1987). Urchei et al. (2000) observaram em duas cultivares de feijão que a área foliar aumentou até aos 30-37 DAE para depois diminuir devido o surgimento de tecidos e estruturas não assimilatórias. Comportamentos decrescentes de área foliar também foram encontrados por Hughes e Freemam (1967) em cultivares de feijão após atingirem o máximo crescimento vegetativo.

As plantas submetidas a $100 \%$ da CC apresentaram valores crescentes de área foliar até aos 43 DAE. Após esse período, percebe-se redução nos valores de área foliar (Figura 2b). Essa redução pode ser atribuída ao período de senescência das folhas, processo que pode ocorrer naturalmente devido ao ciclo fenológico reprodutivo do feijoeiro, que coincide com a floração até a formação das vagens, onde há um favorecimento de alocação de fotoassimilados, em detrimento a manutenção do 
crescimento vegetativo (RITCHIE, 1981). Durante o mesmo estádio de desenvolvimento, ao contrário dos resultados encontrados nas plantas submetidas a $100 \%$ da CC, as plantas submetidas ao tratamento de $50 \%$ da CC mantiveram suas folhas verdes, não apresentando senescência, uma vez que o ciclo fenológico reprodutivo foi atrasado pelo déficit hídrico.

Reduções significativas nos valores do número de nódulos do sistema radicular aos 29, 36, 43, 50,57 e $64 \mathrm{DAE}$, foram encontrados nas plantas submetidas a $50 \%$ da $\mathrm{CC}$ em relação às plantas submetidas a $100 \%$ da CC (Figura 2 c). Os resultados do presente estudo estão de acordo com os obtidos por Coelho e Nascimento (1999), onde verificaram redução no número e no peso da matéria seca dos nódulos das raízes em plantas de feijoeiro caupi submetidas a $40 \%$ da $\mathrm{CC}$ em relação às plantas submetidas a $100 \%$ da CC. Conforme Ramos et al. (1995), a ocorrência de deficiência hídrica durante o ciclo de cultivo do feijoeiro tem efeito negativo em diferentes etapas do processo de nodulação e na atividade nodular, além de afetar a sobrevivência do rizóbio no solo (MARY et al. 1994).

As plantas submetidas a $100 \%$ da CC apresentaram aumento no número de nódulos do sistema radicular a partir dos $22 \mathrm{DAE}$, atingindo um valor máximo aos $43 \mathrm{DAE}$, com posterior queda até o final do experimento (Figura 2c). De acordo com Costa et al. (2006), com o início do período reprodutivo da cultura os nódulos do sistema radicular mais velhos começam a entrar em senescência e em seguida em decomposição, resultando na diminuição no número de nódulos. Diatloff (1967), estudando a produção de nódulos em feijoeiro caupi, encontrou ausência de nódulos durante excessivas condições de umidade e seca, observando perdas dos nódulos com o decréscimo da umidade no solo.

$\mathrm{Na}$ Figura 2d, observou-se reduções significativas na matéria seca aérea de $62,92,132$, $79,58,67,55$ e $17 \%$ aos $15,22,29,36,43,50,57$ e $64 \mathrm{DAE}$, respectivamente, nas plantas submetidas a $50 \%$ da $\mathrm{CC}$ em relação às plantas submetidas à $100 \%$ da CC, mostrando que a restrição hídrica diminui a matéria seca aérea das plantas. No tratamento de $50 \%$ da CC, a matéria seca aérea apresentou reduções significativas para todos os períodos avaliados. Tal fato é devido ao acúmulo e partição da fitomassa seca estar condicionado à disponibilidade de água no solo (LARCHER , 2000). Oliveira et al. (2008), estudando o efeito do estresse hídrico no feijoeiro cultivar capixaba precoce, também constatou que a matéria seca aérea foi menor nas plantas onde havia redução na disponibilidade de água no solo.

Reduções significativas na matéria seca da raiz de $15,106,169,244,265,124,84$ e $24 \%$ aos 22,29 , $36,43,50,57$ e 64 DAE, respectivamente, foram encontrados para as plantas submetidas a $50 \%$ da CC em comparação as plantas submetidas a $100 \%$ da CC (Figura 2e). Segundo Taiz e Zeiger (2009), a resposta positiva de aumento na matéria seca da raiz no tratamento de $100 \%$ da CC está relacionada ao fato de o desenvolvimento do sistema radicular ser dinâmico e extremamente dependente das condições hídricas do solo.

O efeito da restrição hídrica nas plantas de feijoeiro pode ser avaliado pela matéria seca total, que apresentou reduções significativas de 46, 97, $143,119,111,83,63$ e $34 \%$ aos $15,22,36,43,57$, e $64 \mathrm{DAE}$, respectivamente, nas plantas submetidas a $50 \%$ da CC em comparação as plantas submetidas a $100 \%$ da CC (Figura 2f).

Observa-se na Figura 3 que os incrementos de matéria seca total, do caule, da raiz e das folhas ajustaram-se a curva logística. Os incrementos em matéria seca das quatro características avaliadas aumentaram com o tempo independente do tratamento, sendo que as plantas submetidas a $50 \%$ da CC registraram menores valores quando comparados com as plantas submetidas a $100 \%$ da $\mathrm{CC}$, evidenciando que a restrição hídrica reduziu o incremento da matéria seca nas plantas.

Torna-se importante observar que nas plantas submetidas a $100 \%$ da CC houve uma tendência de estabilização no acúmulo de matéria seca total, do caule, da raiz e das folhas no final do ciclo da cultura devido à senescência natural do feijoeiro ao longo de seu ciclo cultural, enquanto nas plantas mantidas a $50 \%$ da CC apresentaram uma tendência de continuar um pequeno crescimento, uma vez que seu desenvolvimento foi retardado pela menor disponibilidade de água presente no solo (Figuras $3 a, 3 b, 3 c$ e 3d). Sob condições de restrição hídrica, o fechamento estomático restringe fortemente a 
fotossíntese e tem sido apontado como a principal limitação da fotossíntese e do acúmulo de matéria seca das plantas (CORNIC 2000). Conforme Stone e Moreira (2001), a ocorrência de estresse hídrico na fase vegetativa do feijoeiro promoverá redução na produtividade. Para Gholz et al. (1990), o decréscimo de água no solo diminui o potencial de água na folha e a condutância estomática, promovendo o fechamento dos estômatos. Este fechamento bloqueia o fluxo de $\mathrm{CO}_{2}$ para as folhas, afetando o acúmulo de fotoassimilados, podendo reduzir a produção.

Observa-se na Figura 4a que, para a massa seca de grãos, houve diferença significativa entre as médias dos tratamentos, verificando que as plantas submetidas a $100 \%$ da CC apresentaram aumento significativo em seus valores, ao passo que as plantas sob restrição hídrica $(50 \%$ da
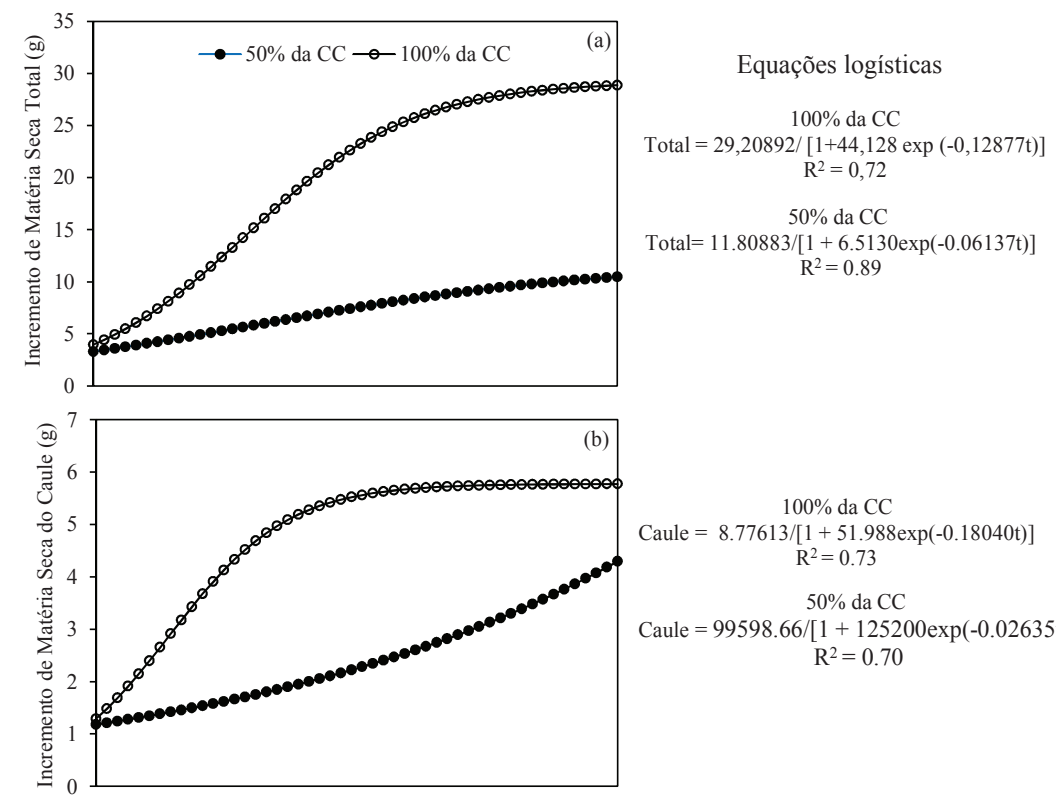

$100 \%$ da CC
Caule $=8.77613 /[1+51.988 \exp (-0.18040 \mathrm{t})]$
$\mathrm{R}^{2}=0.73$
$50 \%$ da CC
Caule $=99598.66 /[1+125200 \exp (-0.02635 \mathrm{t})]$
$\mathrm{R}^{2}=0.70$

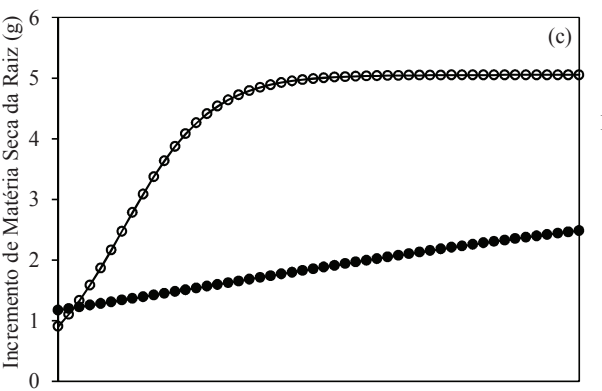

$100 \%$ da CC

Raiz $=5.77613 /[1+51.988 . \exp (-0.18040 \mathrm{t})]$

$\mathrm{R}^{2}=0.64$

$50 \%$ da CC

Raiz $=2.96214 /[1+6.0078 \exp (-0.22367 t)]$

$\mathrm{R}^{2}=0.065$

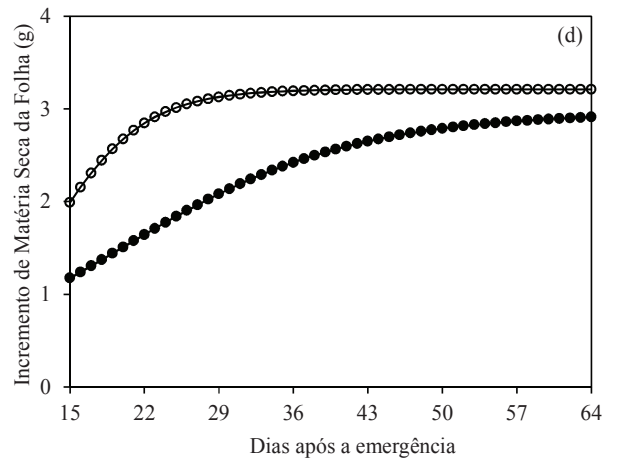

$100 \%$ da CC

$1+183.256 \exp (-0.24618 \mathrm{t})$

Folha $=5.05147 /[1+183.256 x$
$\mathrm{R}^{2}=0.41$

$50 \%$ da CC

Folha $=3.26436 /[1+3.0282 \exp (-0.03545 \mathrm{t})]$
$\mathrm{R}^{2}=0.46$

Figura 3. Incremento de matéria seca total (a), do caule (b), da raiz (c) e das folhas (d) e equações de regressões logísticas e seus respectivos coeficientes de determinação $\left(\mathrm{R}^{2}\right)$ durante o ciclo cultural do feijoeiro submetido a 50 e $100 \%$ da capacidade de campo. 

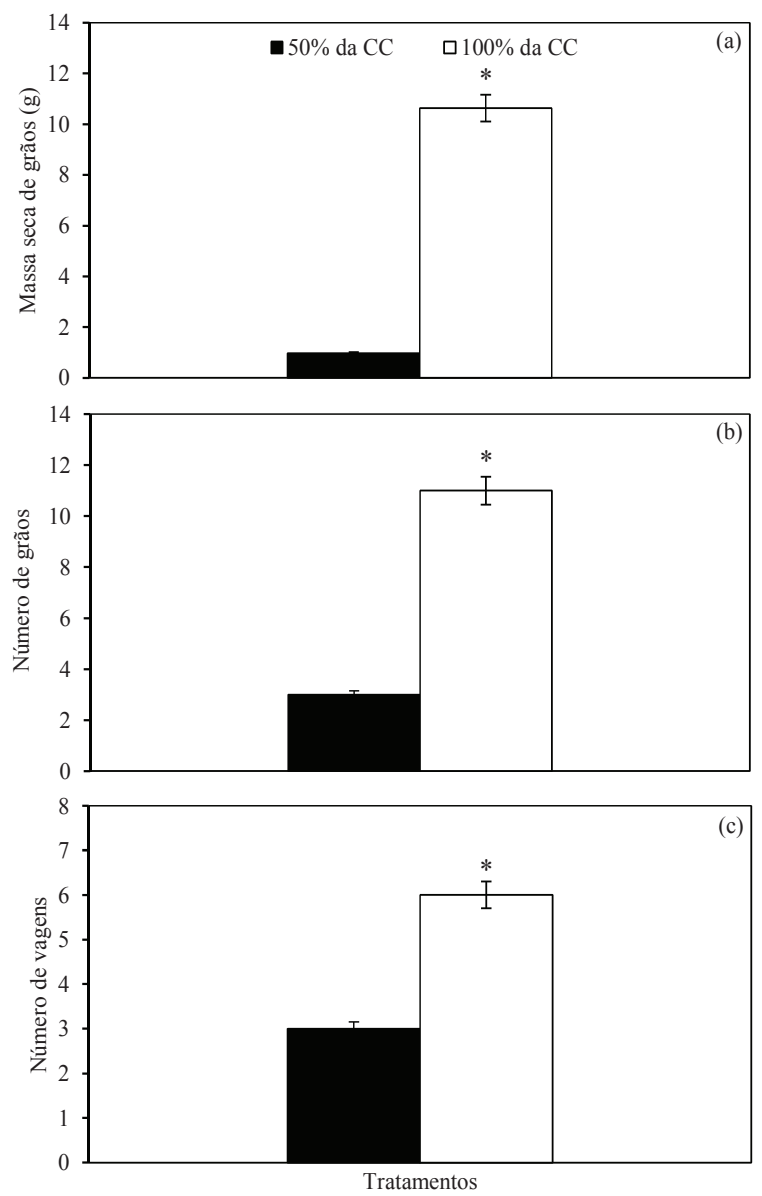

Médias dos tratamentos de 50 e $100 \%$ da capacidade de campo para cada época de avaliação seguidas de asteriscos (*) são significativamente diferentes pelo teste $t$, em nível de $5 \%$ de probabilidade. Barras em cada ponto representam o erro padrão da média.

Figura 4. Massa seca de grãos (a), número de grãos (b) e de vagens (c) durante o ciclo cultural do feijoeiro submetido a 50 e $100 \%$ da capacidade de campo.

CC) apresentaram valores mais baixos. Dessa forma, permite-se deduzir que a restrição hídrica ocasionou um impacto negativo na fase de enchimento de grãos, mostrando o conflito entre a conservação de água pela planta e a taxa de assimilação de $\mathrm{CO}_{2}$ na produção de carboidratos (TAIZ;ZEIGER 2009), afetando assim a produção. Os resultados obtidos para a massa seca de grãos estão de acordo com os resultados obtidos por Fageria et al. (1991), Guimarães (1996), Pimentel e Perez (2000) e mais recentemente Oliveira et al. (2008), confirmando que o estresse hídrico diminuiu significativamente a massa seca de grãos, afetando consideravelmente a produção do feijoeiro. Para o número de grãos também houve diferença significativa entre as médias dos tratamentos nas plantas (Figura 4b). Os valores do número de grãos foram superiores nas plantas submetidas a $100 \%$ da CC quando comparado com as plantas submetidas $50 \%$ da CC, indicando que a restrição hídrica afetou negativamente esse parâmetro. Esses resultados estão de acordo com os obtidos por Pimentel e Perez (2000), que observaram menor número de grãos em diferentes genótipos de feijoeiro submetidos a deficiência hídrica no solo.

$\mathrm{Na}$ Figura 4c, observa-se para o número de vagens, que as plantas submetidas ao tratamento de $100 \%$ da CC apresentaram valores significativamente superiores às plantas submetidas a $50 \%$ da CC. Esses resultados estão de acordo com os obtidos por Garcia et al. (2003),

\section{REVENG $465-475 p$.}


que afirmaram que a deficiência hídrica no solo afetou o rendimento produtivo do feijoeiro, diminuindo o número de vagens.

\section{CONCLUSÕES}

- A restrição hídrica afetou negativamente o crescimento e o rendimento produtivo do feijoeiro, evidenciando a necessidade do controle adequado de água no solo como estratégia de manejo adequado para a produção;

- As análises de crescimento para o feijoeiro mostraram-se capazes de permitir respostas satisfatórias em estudo sobre restrição hídrica.

\section{REFERÊNCIAS BIBLIOGRÁFICAS}

BASTOS, E.A.; RODRIGUES, B.H.N.; ANDRADE JÚNIOR, A.S.; CARDOSO, M.J. Parâmetros de crescimento do feijão caupi sob diferentes regimes hídricos. Engenharia Agrícola, Jaboticabal, v.22, n.1, p.43-50, 2002.

BENINCASA, M. P. Análise de crescimento de plantas. Jaboticabal: Funep, 2003. 41p.

BLUM, A. Crop responses to drought and the interpretation of adaption. In: BELLHASSEN, E (Ed.). Drought tolerance in higher plants: genetical, physiological, and molecular biology analysis. Dordrecht: Kluwer Academic, 1997, p. 57-70.

CARLESSO, R.; JADOSKI, S.O.; MAGGI, M.F.; PETRY, M.; WOLSHICK, D. Efeito da lâmina de irrigação na senescência foliar de feijoeiro. Irriga, Botucatu, v.12, n.4, p.545-556, 2007.

COÊLHO, K.J.F.; NASCIMENTO, R. Nodulação de caupi (Vigna unquiculata (L.) Walp) submetido a déficit hídrico crescente no solo. Agropecuária Técnica, Areia, v.20, n.2, p.58-67, 1999.

COSTA J.V.T.; JUNIOR M.A.L.; FERREIRA R.L.C.; STANFORD N.P.; ARAÚJO F.A.Z. Desenvolvimento de nódulos e plantas de caupi (Vigna unguiculata) por métodos destrutivo e não destrutivo. Revista Caatinga, Mossoró, v.19, p.11-19, 2006.
CORNIC, G. Drought stress inhibits photosynthesis by decreasing stomatal aperture - not by affecting ATP synthesis. Trends in Plant Sciences, Oakland, n.5, p.187-188, 2000.

DIATLOFF, A. Effect of soil moisture fluctuation on legume nodulation and nitrogen fixation in a Black earth soil. Queensland Journal of Agricultural \& Animal Sciences, Husbandry, v.24, p.315-321, 1967.

EMBRAPA - Empresa Brasileira de Pesquisa Agropecuária. Centro Nacional de Pesquisas de Solos. Manual de métodos de análise de solos. 2 ed. Rio de Janeiro: 1997, 212p.

FAGERIA, N.K.; BALIGAR, V.C.; JONES, C. A Common bean and cowpea. Scientia Agrícola, Piracicaba, v.52, n.2, p.339-345, 1995.

FAO, FAOSTAT. http://faostat.fao.org/ acesso em 21 de dezembro de 2009.

FREIRE, J.C.; RIBEIRO, M.V.A.; BAHIA, V.G.; LOPES, A.S.; AQUINO, L.H . Respostas do milho cultivado em casa de vegetação a níveis de água em solos da região de Lavras (MG). Revista Brasileira de Ciência do Solo, Campinas, v.4, n.1, p. $5-8,1980$.

GARCIA, G.O.; LIMA, J.S.S.; FILHO, S.M.; AREAS, M.L.; OLIVEIRA, R.B.; TAGLIAFERRE, C. Efeito do déficit hídrico nos componentes de rendimento de dois cultivares de feijoeiro no município de Alegre, ES. In: CONGRESSO BRASILEIRO DE ENGENHARIA AGRÍCOLA, 22, 2003, Goiânia. Resumos...Goiânia: SBEA, 2003.

GUIMARÃES, C.M.; STONE, L.F.; BRUNINI, O. Adaptação do feijoeiro (Phaseolus vulgaris L.) à seca. II Produtividade e componentes agronômicos. Pesquisa Agropecuária Brasileira, Brasília, v. 1, p.481-488, 1996.

GHOLZ, H.L.; EWEL, K.C.; TESKEY, R.O. Water and forest productivity. Forest Ecological Management, Amsterdam, v.30, p.1-18, 1990. 
HUGHES, A.P.; FREEMAN, P.R. Growth analysis using frequent small harvests. Journal Apliqued Ecoloy, London, v.4, p.553-560, 1967.

HUNT, R. Basic growth analysis-Plant growth analysis for beginners. Unwim Hyman Ltda. London. 1990.

JÚNIOR, P. T. J.; VENZON, M. Manual de tecnologias agrícolas. Belo Horizonte: EPAMIG. 2007. 800p.

LARCHER, W. Ecofisiologia Vegetal. Editora rima. $2000.531 \mathrm{p}$.

MAÑAS, F.M.S.O.; VALERO, J.A.J. 1993. Agronomia Del Riego. Madrid: Mundi-Prensa. $732 p$.

MARRY, P.; DUPUY, N.; DOHLHEM-BIREMON, C.; DEFIVES, C.; TAILliEZ, R. Differences among Rhizobium meliloti and Bradyrhizobium japonicum strains in tolerance to desiccation and storage at different relative humidities. Soil Biology and Biochemistry, Oxford, v.26, p.11251132, 1994.

MOREIRA, J.A.A.; SILVEIRA, P.M.; STONE, L.F. Irrigação. In: ARAÚJO, R.S.; RAVA, C.A.; STONE, L.F.; ZIMMERMANN, M.J.O. (Ed.). Cultura do feijoeiro comum no Brasil. Piracicaba: Potafos, 1996. p.465-522.

MOREIRA, M.F. Desenvolvimento do sistema radicular e da parte aérea do feijoeiro comum em função da distribuição e teor de fósforo no solo. Piracicaba: ESALQ, 2004. 160p. (Tese de Doutorado). Escola Superior de Agricultura Luiz de Queiroz, Piracicaba, São Paulo, 2004.

MÜLLER J.E; WHITSITT M.S. Plant Cellular Responses to Water Deficit In: Drought tolerance in higher plants. Genetical, physiological and molecular biological analysis. Belhassen E. (ed.). Kluwer Academy Publisher, Dordrecht, p.41-46, 1996.

NIELSEN, K.L.; MILLER，C.R.; BECK，D.; LYNCH, J.P. Fractal geometry of root system: Fiel observations of contrastings genotype of common bean (Phaseolus vulgaris L.) grown unde different phosphorus regimes. Plant and Soil, v.206, p.181190, 1999.

NÓBREGA, J.Q; RAO, T.V.R; BELTRÃO, N.E.M.; FILHO, J.F. Análise de crescimento do feijoeiro submetido a quatro níveis de umidade do solo. Revista Brasileira de Engenharia Agrícola e Ambiental, Campina Grande, v.5, p.437-443, 2001.

OLIVEIRA, R.B.; LIMA, J.S.S.; REIS, E.F.; PEZZOPANE, J.E.M.; SILVA, A. F. Níveis de déficit hídrico em diferentes estádios fenológicos do feijoeiro (Phaseolus vulgaris L., cv. capixaba precoce). Engenharia na Agricultura, Viçosa, v.16, n.3, p.343-350, 2008.

PAÉZ, A.; GONZÁLES, M.E.; YRAUSQUÍN, O.X. 1995. Water stress and clipping management effects on guinea grass. In: Growth and biomass allocation. Agronomy Journal, Madison, v.87, p.698-706, 1995.

PASSIOURA, J.B. Drought and drought tolerance. In: Drought tolerance in higher plants. Genetical, physiological and molecular biological analysis. Belhassen E. (ed.). Kluwer Academy Publisher, Dordrecht, p.1-15, 1997.

PEREIRA, A.R.; MACHADO, E.C. Análise quantitativa do crescimento de comunidades vegetais. Boletim Técnico, 114. Campinas: IAC, 1987.33p.

PIMENTEL, C.; PEREZ, A.J.C. Estabelecimento de paramentos para avaliação de tolerância à seca, em genótipos de feijoeiro. Pesquisa Agropecuária Brasileira, Brasília, v.35, n.1, p.31-39, 2000.

RAMOS, M.L.G.; PARSONS, P.; JAMES, E.K.; SPRENT, J.I. Effect of water stress on nitrogen-fixation of two cultivars of common bean (Phaseolus vulgaris L). In: Tikonovich Ia, Provorov NA, Newton WE. (Ed.). Nitrogne Fixation: fundamentals and applications. Dordrecht: Klumer, 1995, p.728.

RITCHIE, J.T. Water dynamics in the soil-plantatmosphere system. Plant and Soil, Hage, v.58, p.81-96, 1981. 
ROSELEM, A.C.; MARUBAYASHI, M.A. Seja doutor de seu feijoeiro. Arquivo do Agrônomo, São Paulo, n.7, p.1-18, 1994.

STONE, L.F.; MOREIRA, J.A.A. Respostas do feijoeiro ao nitrogênio em cobertura, sob diferentes lâminas de irrigação e preparos do solo. Pesquisa Agropecuária Brasileira, Brasília, v.36, n.3, p.473-481, 2001.
TAIZ, L.; ZEIGER E. Fisiologia vegetal. 4 ed. Porto Alegre: Artemed, 2009. 819p.

URCHEI, M.A.; RODRIGUES, J.D.; STONE, L.F. Análise de crescimento de duas cultivares de feijoeiro sob irrigação em plantio direto e preparo convencional. Pesquisa Agropecuária Brasileira, Brasília, v.35, n.3, p.497-506, 2000. 